\section{The Effects of Aminoethoxyvinylglycine and Naphthaleneacetic Acid Treatments on Abscission and Firmness of 'Scarletspur Delicious' Apples at Normal and Delayed Harvests}

\author{
C.R. Unrath ${ }^{1}$, J.D. Obermiller ${ }^{1}$, A. Green ${ }^{1}$, \\ and S.J. McArtney ${ }^{1,2}$
}

Additional Index words. AVG, ReTain, NAA, Fruitone, Malus $\times$ domestica, fruit quality

Summary. The variation in natural fruit drop of 'Scarletspur Delicious' /'M.7' (M.7) apple (Malus $\times$ domestica) trees in a commercial orchard over a period of 11 consecutive years was visualized using box and whisker plots. Delaying harvest until 1 week after the normal harvest date resulted in fruit drop ranging from $2 \%$ to $33 \%$ depending on the year. The effects of aminoethoxyvinlyglycine (AVG) and naphthaleneacetic acid (NAA) on fruit drop and fruit firmness at normal and delayed harvests was monitored each year. AVG and NAA programs tended to mitigate fruit drop most effectively in years when natural fruit drop was heavy. AVG delayed the loss of fruit firmness, whereas a preload NAA program delayed firmness loss in fruit that were harvested 3 weeks after the normal harvest date only. A standard NAA program for drop control did not accelerate softening of 'Scarletspur Delicious' during the first 3 weeks after the normal harvest date. Growers should closely monitor fruit maturity and stem loosening during the harvest window each year to minimize the risk of major losses due to fruit drop. When timely harvest is not possible, perhaps due to unforeseen weather events or constraints in labor availability, or poor management, then use of harvest management aids such as AVG or NAA becomes critical on cultivars prone to fruit drop.

$\mathrm{P}$ reharvest fruit drop can reduce production of some modern apple cultivars in commercial orchards by as much as $30 \%$ (Marini et al., 1993). A recent determination of natural variation in fruit abscissionrelated traits in apple suggested that preharvest fruit drop can occur independently of fruit ethylene production (Sun et al., 2009). Losses resulting from preharvest fruit drop can be mitigated by applying either naphthaleneacetic acid (NAA; Fruitone L; AMVAC Chemical, Newport Beach, CA) or aminoethoxyvinlyglycine (AVG; Retain; Valent BioSciences, Libertyville, IL) to delay drop. Holding fruit on the tree beyond the normal harvest date may also increase crop value due to an increase in fruit size (yield) and improvement in red

\footnotetext{
We thank Mr. Billy Mckay for his cooperation.

${ }^{1}$ Department of Horticultural Science, North Carolina State University, Mountain Horticultural Crops Research and Extension Center, 455 Research Drive, Fletcher, NC 28732

${ }^{2}$ Corresponding author. E-mail: steve_mcartney@
} ncsu.edu. color development. Byers and Eno (2002) estimated that delaying harvest for an additional 3 weeks increased crop value by as much as $20 \%$ due to an increase in fruit size and improvement in fruit color; provided fruit maturity was not also advanced during this period.

Gardner et al. (1939) provided the first report that NAA delayed fruit drop. NAA delayed fruit drop most effectively when applied at concentrations of 5 to $20 \mathrm{mg} \cdot \mathrm{L}^{-1} 3$ to 4 weeks before the optimum harvest date and then again 14 to $21 \mathrm{~d}$ later (Marini et al., 1993). Many growers remain cautious about using preharvest NAA sprays for drop control because of the risk of accelerated fruit softening that they occasionally observe and that has been demonstrated in some studies (Batjer and Moon, 1945; Byers, 1997a; Greene and Schupp, 2004; $\mathrm{Li}$ and Yuan, 2008; Marini et al., 1993; Schupp and Greene, 2004; Yuan and $\mathrm{Li}, 2008$ ). Growers in the southeastern United States commonly apply NAA as four sprays of 5 $\mathrm{mg} \cdot \mathrm{L}^{-1}$ at weekly intervals beginning 4 weeks before the normal harvest date in a program referred to as "preload NAA" (PL-NAA). The supposed advantage of a PL-NAA program is that it provides equivalent drop control compared with a standard NAA program without the risks of accelerated fruit softening associated with higher rates of NAA. The reduction in fruit drop following preharvest NAA sprays was associated with reduced expression of genes involved in cell wall degradation (MdPG2 and MdEGl) in the fruit abscission zone (Li and Yuan, 2008). However, preharvest NAA sprays also increased ethylene production and softening in the fruit cortex, associated with increased expression of genes involved in ethylene biosynthesis (MdACSI and $\mathrm{MdACOI}$ ) and perception (MdERS1) and cell wall degradation (MdPGl) (Li and Yuan, 2008).

The control of preharvest drop in apples with AVG was first described by Bangerth (1978). AVG is typically applied $28 \mathrm{~d}$ before the anticipated harvest date and reduces fruit drop by suppressing expression of genes involved in ethylene biosynthesis (MdACS5A, MdACS5B, and MdACOl) and cell wall degradation (MdPG2 and MdEGl) in the fruit abscission zone ( $\mathrm{Li}$ and Yuan, 2008; Yuan and Li, 2008). AVG also inhibited ethylene production and delayed softening in fruit by suppressing the expression of MdACS1, MdACOl, MdERS1, and MdPGl in the fruit cortex $(\mathrm{Li}$ and Yuan, 2008).

\begin{tabular}{llll}
\hline $\begin{array}{l}\text { Units } \\
\text { To convert U.S. to SI, } \\
\text { multiply by }\end{array}$ & U.S. unit & SI unit & $\begin{array}{l}\text { To convert SI to U.S., } \\
\text { multiply by }\end{array}$ \\
\hline 0.4047 & acre(s) & ha & 2.4711 \\
9.3540 & gal/acre & $\mathrm{L} \cdot \mathrm{ha}^{-1}$ & 0.1069 \\
25.4 & inch $(\mathrm{es})$ & $\mathrm{mm}$ & 0.0394 \\
4.4482 & $\mathrm{lbf}$ & $\mathrm{N}$ & 0.2248 \\
28.3495 & $\mathrm{oz}$ & $\mathrm{g}$ & 0.0353 \\
1 & $\mathrm{ppm}$ & $\mathrm{mg} \cdot \mathrm{L}^{-1}$ & $\mathrm{l}$
\end{tabular}


Numerous studies have compared the relative efficacy of AVG and standard NAA programs for fruit drop control in apple (Byers, 1997a, 1997b; Dal Cin et al., 2008; Greene, 2005; Greene and Schupp, 2004; Li and Yuan, 2008; Schupp and Greene, 2004; Yuan and Carbaugh, 2007; Yuan and Li, 2008). However, with one exception, these comparisons were restricted to different groups of trees in individual years. In only one instance was the efficacy of AVG and standard NAA treatments for drop control directly compared in the same orchard over two consecutive seasons (Greene, 2005). To our knowledge, there have been no studies comparing the effects of AVG and NAA treatments on fruit drop or fruit firmness at normal and delayed harvests within the same apple orchard over a prolonged period. This article describes natural patterns of fruit drop within a commercial orchard of 'Scarletspur Delicious' apples over a period of 11 years (consecutive) and compares the effects of AVG, standard NAA, and PL-NAA treatments on fruit drop and fruit firmness within the same orchard.

\section{Materials and methods}

Thirty-two mature 'Scarletspur Delicious' trees on M.7 rootstock were selected from within a commercial orchard in Henderson County, NC, each year from 1991 to 2001. The trees were grouped into 16 pairs (plots), each plot separated by at least one buffer tree. One tree in each plot was used to collect harvest samples for firmness measurements, while the second tree was used to follow the progression of fruit drop. The trees were arranged into four blocks with four two-tree plots in each block. One plot in each block received AVG (ABG-3097; Abbott Laboratories, North Chicago, IL) at a rate equivalent to $50 \mathrm{~g} /$ acre a.i. with $0.1 \%$ surfactant (ABG-7034; Abbott Laboratories) $28 \mathrm{~d}$ before the anticipated harvest date. A second plot in each block received a standard NAA program of $10 \mathrm{mg} \cdot \mathrm{L}^{-1} \mathrm{NAA}$ as Fruitone $\mathrm{N}$ (AMVAC Chemical) applied 2 weeks and 1 week before the anticipated harvest date. A third plot received four applications of $5 \mathrm{ppm}$ $\mathrm{NAA}$ as Fruitone $\mathrm{N}$ at weekly intervals beginning 4 weeks before the anticipated harvest date (PL-NAA). No surfactant was included with the NAA sprays. The remaining plot in each block was left as an untreated control. The spray treatments were applied with a power takeoff-driven, air-assist, axial fan sprayer calibrated to deliver $200 \mathrm{gal} / \mathrm{acre}$. A different group of trees was used each year to avoid potential carry-over effects.

A random sample of 20 fruit was removed from the harvest sample tree in each plot at weekly intervals beginning at the normal harvest date for untreated trees. Fruit firmness was measured on opposite pared sides of each fruit with a penetrometer (Effegi, Alfonsine, Italy) fitted with an 11.1-mm tip. Firmness data were only available for the normal harvest date in 1991, but for each of the remaining years, fruit firmness was measured at weekly intervals until 3 weeks after the normal harvest date. The number of fruit beneath the second tree in each plot was counted at weekly intervals for 7 weeks beginning at the normal harvest date each year. The number of fruit remaining on the tree at the end of the experiment each year was counted. Fruit drop records were not available for the AVG treatment in 1991 or for the PL-NAA treatment in 1995.

Cumulative fruit drop over time was calculated as a percentage of total fruit number per tree. Yearly variation in fruit drop and firmness were visualized using box and whisker plots where each plot represented a summary of the yearly mean values $(\mathrm{n}=$ 11). Outliers and suspected outliers were identified as individual data points that were 3 or 1.5 times greater than the interquartile range (the difference between the 75 th quartile and the 25th quartile), respectively. Cumulative fruit drop data were further analyzed using the Mixed Model procedure of SAS (version 9.1; SAS Institute, Cary, NC) to test for significant main effects of treatments and year, and for the interaction between treatment and year, specifying block ( $\mathrm{n}=4$ each year) as a random effect in the model. Correlation analysis of the relationship between cumulative fruit drop on treated versus control trees, using the mean values from all 11 years, was used to explore the relationship between natural fruit drop and the performance of the different stop drop treatments across all years.

\section{Results and discussion}

NATURAL FRUIT DROP. There was considerable variation among years in natural fruit drop at the normal harvest date and during the 6 weeks following the normal harvest date. This variation is visualized by the box and whisker plots in Fig. 1 . Whereas the median value for natural fruit drop at the normal harvest date was only $3 \%$, the minimum and maximum values were $1 \%$ and $17 \%$, respectively. Natural fruit drop increased over time with median values of $8 \%, 25 \%$, and $50 \%$ at 1,2 , and 3 weeks after the normal harvest date in each year, respectively. Cumulative fruit drop data during the first 2 weeks of harvest in 1996, the year of heaviest natural fruit drop, were suspected outliers. The reasons for the large differences in natural fruit drop among years are not clear. While it seems logical that fruit drop might be greater in hot years where fruit ripening may be accelerated, it appears that apple fruit abscission can occur independently of fruit ethylene production (Sun et al., 2009).

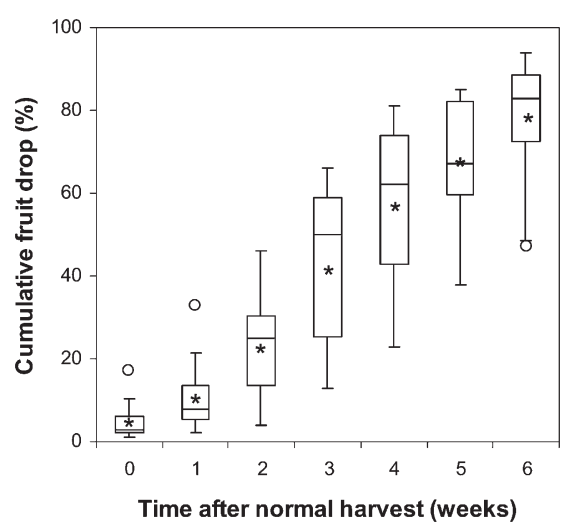

Fig. 1. Box and whisker plots visualizing the variation in cumulative natural fruit drop of 'Scarletspur Delicious' apples at weekly intervals after the normal harvest date in a commercial orchard in Henderson County, NC. Each plot represents a summary of yearly mean cumulative fruit drop values ( $n=4$ each year) from 11 years (consecutive). The horizontal line and asterisk within each box represent median and mean cumulative fruit drop values across all years, respectively. Open circles beyond the whiskers represent suspected outliers; data points more than 1.5 times the interquartile range above the third quartile. 
Delaying harvest by just 1 week after the normal harvest date resulted in fruit drop anywhere between 2\% and $33 \%$ of the total fruit number, depending on the year. These data are in agreement with earlier findings that preharvest fruit drop can reduce fruit number in commercial apple orchards by as much as $30 \%$ (Marini et al., 1993). The risk of a major loss of fruit resulting from delaying harvest by just 1 week reinforces the need for close monitoring of fruit maturity and stem loosening leading up to harvest. In situations where timely harvest is not possible, perhaps due to unforeseen weather events or constraints in labor availability, or poor management, then the use of effective harvest management aids becomes critical.

Efficacy of AVG and NAA. Data describing the effects of AVG and NAA treatments on fruit drop (Fig. 2) and firmness (Fig. 3) are visualized as box and whisker plots for the normal harvest date and the following 3 weeks each year. While the effects of these materials on fruit drop later than 3 weeks after the normal harvest date may be of academic interest, they are likely to be of minimal practical significance because fruit firmness values would typically fall below commercially acceptable limits by 3 weeks after the normal harvest date in most years. The data in Fig. 2 reveal that none of the drop control treatments greatly reduced fruit drop at the time of normal harvest each year. However, cumulative fruit drop was reduced to a similar level by $\mathrm{AVG}$, NAA, and PL-NAA treatments during the following 3 weeks compared with the control. By 3 weeks after the normal harvest date, there was a trend for AVG to control fruit drop more effectively than the standard NAA or PL-NAA treatments (Fig. 2D), which became more pronounced with time (see data in Fig. 4).

The drop control treatments did not greatly influence fruit firmness throughout the study period, although the plots for 2 weeks (Fig. 3C) and 3 weeks (Fig. 3D) after the normal harvest date indicate a tendency for AVG to delay softening compared with the control. Further analysis of treatment effects on fruit firmness using mean yearly data from all years $(n=11)$ revealed a reduction in the loss of firmness following AVG treatment at the normal harvest date (0.7 lbf, $P=0.003)$ and 2 weeks $(0.6$ lbf, $P=0.01)$ or 1 week $(0.6 \mathrm{lbf}, P=$ 0.01 ) after the normal harvest date compared with the control. This analysis also revealed that PL-NAA delayed the loss of fruit firmness 3 weeks after the normal harvest date (0.5 lbf, $P=0.03)$ but that firmness of
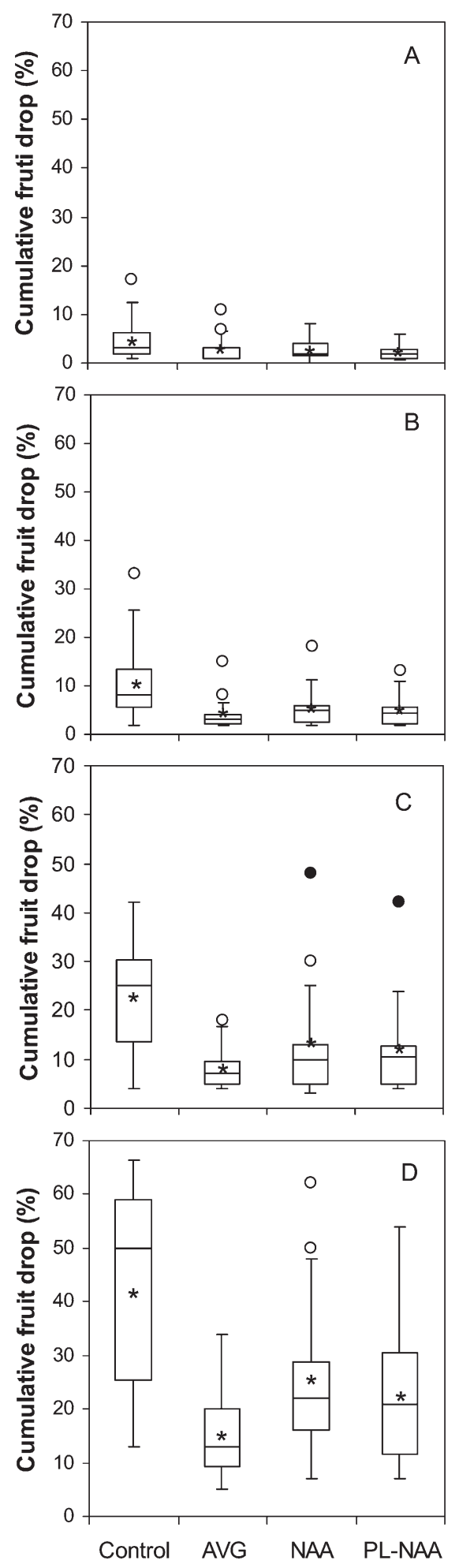

fruit from the control and standard NAA treatments were not different at any harvest date. Previous reports have demonstrated that NAA can occasionally accelerate fruit softening (Batjer and Moon, 1945; Byers, 1997b; Greene and Schupp, 2004; $\mathrm{Li}$ and Yuan, 2008; Marini et al., 1993; Schupp and Greene, 2004; Yuan and Li, 2008); however, it has been suggested that this response is more common when NAA is applied at higher rates $\left(20 \mathrm{mg} \cdot \mathrm{L}^{-1}\right)$ or when warm weather follows the first of multiple NAA sprays (Yuan and Li, 2008). Combinations of AVG and NAA have been shown to provide better control of fruit drop compared with either material alone and negate the potential for NAA to accelerate fruit softening (Yuan and Li, 2008). We recently found that reduced rates of AVG in combination with NAA controlled fruit drop more effectively than a full rate of AVG alone without adversely affecting fruit firmness (S. McArtney, unpublished data). Combining AVG and NAA sprays for drop control may offer growers an effective

Fig. 2. Box and whisker plots visualizing the effects of aminoethoxyvinlyglycine (AVG) and naphthaleneacetic acid (NAA) programs for drop control in a commercial 'Scarletspur Delicious' apple orchard in Henderson County, NC. AVG was applied as $50 \mathrm{~g}(1.8 \mathrm{oz})$ per acre $\left(123.6 \mathrm{~g} \cdot \mathrm{ha}^{-1}\right)$ a.i. 4 weeks before the anticipated harvest date each year. NAA was applied as two sprays of $10 \mathrm{mg} \cdot \mathrm{L}^{-1}(\mathrm{ppm}) 2$ weeks and 1 week before the anticipated harvest date (NAA) or as four applications of 5 $\mathrm{mg} \cdot \mathrm{L}^{-1}$ at weekly intervals beginning 4 weeks before the anticipated harvest date [preload NAA (PL-NAA)]. Fruit drop was measured at the normal harvest date (A), or 1 week (B), 2 weeks (C), and 3 weeks (D) later. Each plot represents a summary of yearly mean cumulative fruit drop values $(n=4$ each year) from 11 years (consecutive). The horizontal line and asterisk within each box represent the median and mean cumulative fruit drop values across all years, respectively. Open circles beyond the whiskers represent suspected outliers; data points more than $\mathbf{1 . 5}$ times the interquartile range above the third quartile. Closed circles beyond the whiskers represent outliers; data points more than three times the interquartile range above the third quartile. 

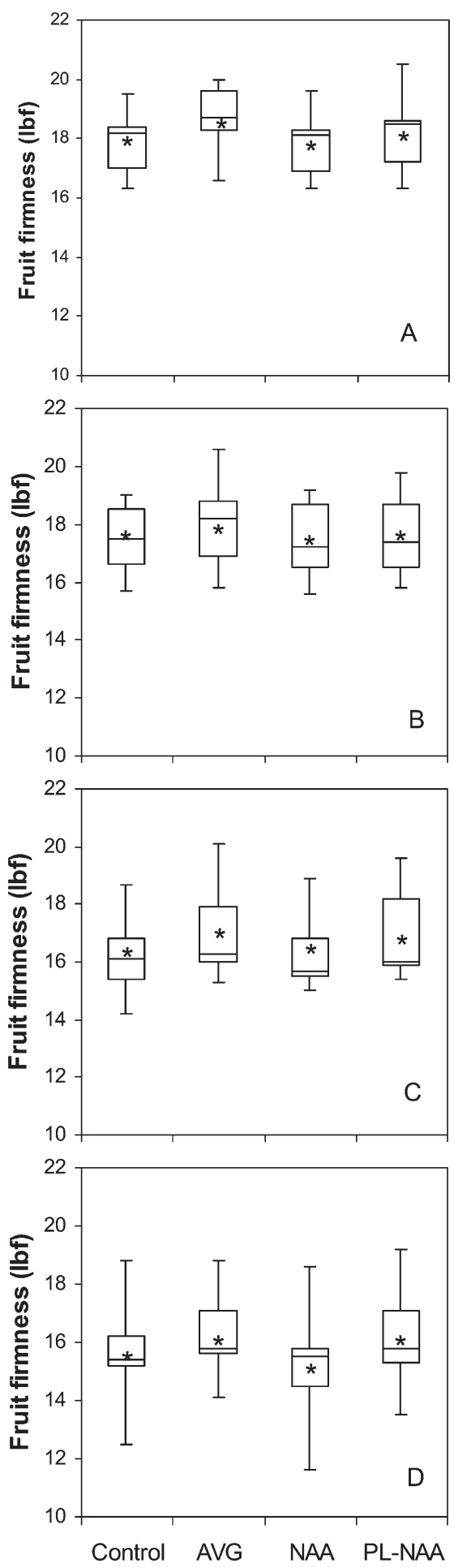

strategy for mitigating losses due to fruit drop in situations where the risks of accelerated fruit softening associated with a standard NAA treatment for drop control are unacceptable.

DIFFERENCES IN EFFICACY OF AVG AND NAA AMONG YEARs. There was considerable yearly variation in
Fig. 3. Box and whisker plots

visualizing the effects of

aminoethoxyvinlyglycine (AVG) and

naphthaleneacetic acid (NAA)

programs for drop control on fruit

firmness in a commercial 'Scarletspur

Delicious' apple orchard in Henderson

County, NC. AVG was applied as $50 \mathrm{~g}$

$(1.8 \mathrm{oz})$ per acre $\left(123.6 \mathrm{~g} \cdot \mathrm{ha}^{-1}\right)$ a.i. 4

weeks before the anticipated harvest

date each year. NAA was applied as two

sprays of $10 \mathrm{mg} \cdot \mathrm{L}^{-1}(\mathrm{ppm}) 2$ weeks and

1 week before the anticipated harvest date (NAA) or as four sprays of 5 $\mathrm{mg} \cdot \mathrm{L}^{-1}$ at weekly intervals beginning 4 weeks before the anticipated harvest date [preload NAA (PL-NAA)]. Fruit firmness was measured at the normal harvest date (A), and 1 week (B), 2 weeks (C), or 3 weeks (D) later. Each plot represents a summary of yearly mean fruit firmness values $(n=4$ each year) from 11 years (consecutive). The horizontal line and asterisk within each box represent the median and mean fruit firmness values across all years, respectively; $1 \mathrm{lbf}=4.4482 \mathrm{~N}$.

efficacy of the different drop control treatments (Fig. 2). All three drop control treatments had their greatest effect in 1996, which was also the year of greatest natural fruit drop (Fig. $4 \mathrm{~A}$ ). The treatments had little or no effect on fruit drop 3 weeks after the normal harvest date in 1997, which was also the year of lowest natural fruit drop (Fig. 4B). Interestingly, AVG was the only treatment to reduce fruit drop in 1997; however, this effect was not observed until later than 3 weeks after the normal harvest date (Fig. 4B). There was a significant treatment $x$ year interaction term in the analysis of cumulative fruit drop across all years (Table 1). The inference from these observations is that drop control treatments have their greatest activity in years of high natural fruit drop and exhibit little or no activity in years of low natural fruit drop.

The relationship between yearly mean values for natural fruit drop and fruit drop on treated trees was explored for each treatment across all years using the Pearson product moment correlation coefficient $(r)$ (Fig. 5). This approach revealed a positive linear relationship between the level of natural fruit drop and fruit drop control resulting from each treatment, measured 3 weeks after the normal harvest date. Most of the individual data points fall below the $1: 1$ line, indicating that the treatments generally reduced cumulative fruit drop 3 weeks after the normal harvest date. NAA had no effect on fruit drop in 1991 and even resulted in higher fruit drop than the control in 1995. In contrast, PL-NAA did not influence fruit drop in 1991. The relationships described in Fig. 5
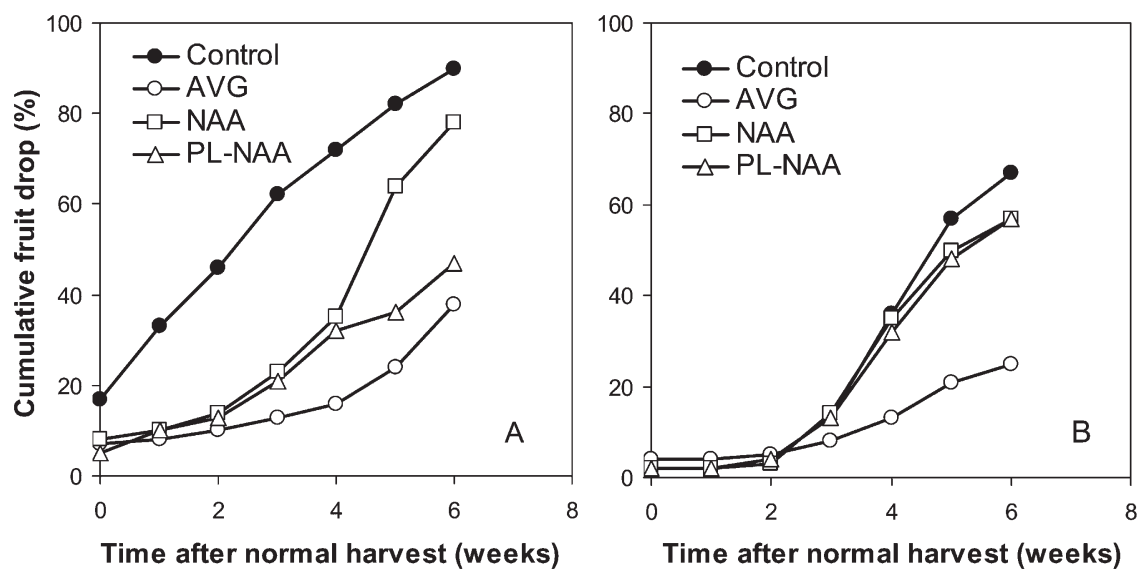

Fig. 4. Effects of aminoethoxyvinlyglycine (AVG), naphthaleneacetic acid (NAA), and preload NAA (PL-NAA) programs on cumulative fruit drop of 'Scarletspur Delicious' apples in Henderson County, NC, in 1996, a year of severe natural drop (A) and in 1997, a year of minimal natural drop (B). AVG was applied as $50 \mathrm{~g}$ (1.8 oz) per acre $\left(123.6 \mathrm{~g} \cdot \mathrm{ha}^{-1}\right)$ a.i. 4 weeks before the anticipated harvest date each year. NAA was applied as two sprays of $10 \mathrm{mg} \cdot \mathrm{L}^{-1}(\mathrm{ppm}) 2$ weeks and 1 week before the anticipated harvest date (NAA) or as four sprays of $5 \mathrm{mg} \cdot \mathrm{L}^{-1}$ at weekly intervals beginning 4 weeks before the anticipated harvest date (PL-NAA). Data points represent the mean of four single-tree replications. 
Table 1. Analysis of variance of effects of drop control treatments on cumulative fruit drop of 'Scarletspur Delicious' apple measured weekly for $\mathbf{5}$ weeks after the normal harvest date over 10 consecutive years. Aminoethoxyvinylglycine was applied as $50 \mathrm{~g}(1.8 \mathrm{oz})$ per acre $\left(123.6 \mathrm{~g} \cdot \mathrm{ha}^{-1}\right)$ a.i. 4 weeks before the anticipated harvest date each year. Naphthaleneacetic acid was applied as two sprays of $10 \mathrm{mg} \cdot \mathrm{L}^{-1}(\mathrm{ppm}) 2$ weeks and 1 week before the anticipated harvest date (NAA) or as four sprays of $5 \mathrm{mg} \cdot \mathrm{L}^{-1}$ at weekly intervals beginning 4 weeks before the anticipated harvest date [preload NAA (PL-NAA)]. The three drop control treatments and an untreated control were assigned to four single-tree plots arranged in a randomized complete block design experiment each year. Data from all years were combined and analyzed after specifying block as a random effect in the model.

\begin{tabular}{lrrrrrr}
\hline & \multicolumn{7}{c}{ Pvalue } \\
\cline { 2 - 7 } Effect & Week 0 & Week 1 & Week 2 & Week 3 & Week 4 & Week 5 \\
\hline Treatment & 0.2014 & $<0.0001$ & $<0.0001$ & $<0.0001$ & $<0.0001$ & $<0.0001$ \\
Year & $<0.0001$ & $<0.0001$ & $<0.0001$ & $<0.0001$ & $<0.0001$ & $<0.0001$ \\
Year $\times$ Treatment & 0.0593 & 0.0803 & 0.0364 & 0.0003 & $<0.0001$ & $<0.0001$ \\
\hline
\end{tabular}

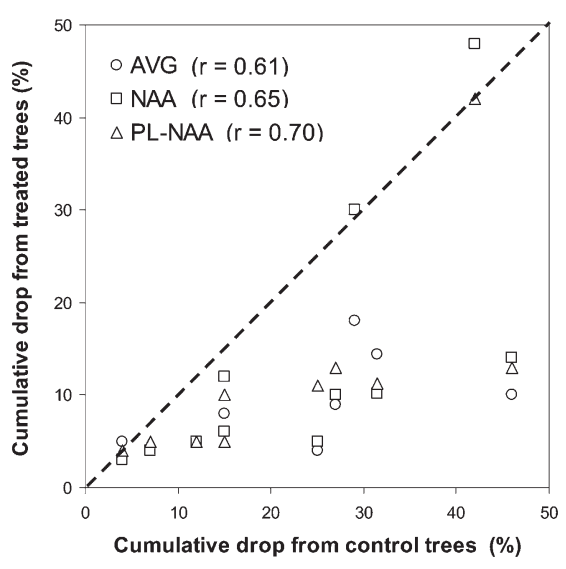

Fig. 5. Relationship between cumulative natural fruit drop and cumulative fruit drop from trees treated with aminoethoxyvinlyglycine (AVG), naphthaleneacetic acid (NAA), and preload NAA (PL-NAA)

treatments, measured 3 weeks after the normal harvest date. AVG was applied as $50 \mathrm{~g}(1.8 \mathrm{oz})$ per acre $\left(123.6 \mathrm{~g} \cdot \mathrm{ha}^{-1}\right)$ a.i. 4 weeks before the anticipated harvest date each year. NAA was applied as two sprays of $10 \mathrm{mg} \cdot \mathrm{L}^{-1}$ (ppm) 2 weeks and 1 week before the anticipated harvest date (NAA) or as four sprays of $5 \mathrm{mg} \cdot \mathrm{L}^{-1}$ at weekly intervals beginning 4 weeks before the anticipated harvest date (PL-NAA). Data points represent mean yearly cumulative fruit drop values for individual treatments in each year. The Pearson product moment correlation coefficient (r) describing the linear relationship between each treatment and the control across all years is listed in the legend. Dashed line represents $1: 1$ ratio between the two variables.

suggest that drop control treatments tended to be less effective in years of low natural fruit drop, but increasingly effective in years of high natural fruit drop. Thus, there is little apparent advantage in applying drop control treatments when the level of natural fruit drop is low unless the grower is applying AVG to obtain increases in fruit size by delaying harvest without sacrificing fruit firmness. Unfortunately, there is currently no means of predicting how severe fruit drop will be at the time when AVG is normally applied. NAA may require only 2 to $3 \mathrm{~d}$ before slowing fruit drop, therefore it can be used by growers reactively to delay fruit drop rather than proactively as for AVG.

\section{Conclusion}

Natural fruit drop in a commercial 'Scarletspur Delicious' apple orchard exhibited considerable variation over an 11-year period. Delaying harvest until 1 week after the normal harvest date reduced the number of fruit by $33 \%$ in the most severe drop year, reinforcing the need for close monitoring of fruit maturity and stem loosening each year. AVG, standard NAA, and PL-NAA programs reduced fruit drop in most years; their activity as stop-drop sprays tended to be greater in years of highest natural fruit drop. AVG resulted in fruit that were 0.6 to 0.7 lbf firmer than the controls when harvest was delayed by as much as 3 weeks after the normal date, whereas there was no evidence that NAA programs accelerated fruit softening of 'Scarletspur Delicious' in the present study. Use of harvest management aids such as AVG or NAA are an important tool for mitigating losses due to fruit drop on susceptible cultivars when timely harvest is not possible or when fruit are held on the tree beyond the normal harvest date to achieve increased size or improve red color development.

\section{Literature cited}

Bangerth, F. 1978. The effect of a substituted amino acid on ethylene biosynthesis, respiration, ripening, and preharvest drop of apple fruit. J. Amer. Soc. Hort. Sci. 103:401-404.

Batjer, L.P. and H.H. Moon. 1945. Effect of naphthaleneacetic acid sprays on maturity of apples. Proc. Amer. Soc. Hort. Sci. 46:113-117.

Byers, R.E. 1997a. Effects of aminoethoxyvinylglycine (AVG) on preharvest fruit drop, maturity, and cracking of several apple cultivars. J. Tree Fruit Production 2:77-97.

Byers, R.E. 1997b. Effects of aminoethoxyvinylglycine (AVG) on preharvest fruit drop and maturity of 'Delicious' apples. J. Tree Fruit Production 21:53-76.

Byers, R.E. and D.R. Eno. 2002. Harvest date influences size and yield of 'York' and 'Golden Delicious' apple trees. Intl. J. Fruit Sci. 3:63-79.

Dal Cin, V., A. Dorigoni, A. Ramina, A. Boschetti, M. Danesin, and A. Botton. 2008. Ethylene and preharvest drop: The effect of AVG and NAA on fruit abscission in apple (Malus domestica L. Borkh). Plant Growth Regulat. 56:317-325.

Gardner, F.E., P.C. Marth, and L.P. Batjer. 1939. Spraying with plant growth substances to prevent apple fruit dropping. Science 90:208-209.

Greene, D.W. 2005. Time of aminoethoxyvinylglycine application influences preharvest drop and fruit quality of 'McIntosh' apples. HortScience 40: 2056-2060.

Greene, D.W. and J.R. Schupp. 2004. Effect of aminoethoxyvinylglycine (AVG) on preharvest drop, fruit quality, and maturation of 'McIntosh' apples. II. Effect of timing and concentration relationships and spray volume. HortScience 39:1036-1041.

Li, J. and R. Yuan. 2008. NAA and ethylene regulate expression of genes related to ethylene biosynthesis, perception, and cell wall degradation during fruit abscission and ripening in 'Delicious' apples. J. Plant Growth Regul. 27:283-295.

Marini, R.P., R.E. Byers, and D.L. Sowers. 1993. Repeated applications of NAA control preharvest drop of 'Delicious' apples. J. Hort. Sci. 68:247-253. 
Schupp, J.R. and D.W. Greene. 2004. Effect of aminoethoxyvinylglycine (AVG) on preharvest drop, fruit quality, and maturation of 'McIntosh' apples. I. Concentration and timing of dilute applications of AVG. HortScience 39:1030-1035.

Sun, L., M.J. Bukovac, P.L. Forsline, and S. van Nocker. 2009. Natural variation in fruit abscission-related traits in apple (Malus). Euphytica 165:55-67.

Yuan, R. and D. Carbaugh. 2007. Effects of NAA, AVG, and 1-MCP on ethylene biosynthesis, preharvest fruit drop, fruit maturity, and quality of 'Golden Supreme' and 'Golden Delicious' apples. HortScience 42:101-105.
Yuan, R. and J. Li. 2008. Effect of sprayable 1-MCP, AVG, and NAA on ethylene biosynthesis, preharvest fruit drop, fruit maturity, and quality of 'Delicious' apples. HortScience 43:1454-1460. 